\title{
Adubação, produtividade e rentabilidade da rotação entre soja e milho em solo com fertilidade construída
}

\author{
Julian Junio de Jesús Lacerda ${ }^{(1)}$, Álvaro Vilela de Resende ${ }^{(2)}$, Antonio Eduardo Furtini Neto(1), \\ Clério Hickmann ${ }^{(1)}$ e Otávio Prates da Conceição ${ }^{(3)}$
}

(1)Universidade Federal de Lavras, Departamento de Ciência do Solo, Caixa Postal 3.037, CEP $37200-000$ Lavras, MG, Brasil.
E-mail: julianlacerda@gmail.com, afurtini@dcs.ufla.br, clerioh@gmail.com ${ }^{(2)}$ Embrapa Milho e Sorgo, Rodovia MG-424, Km 45, Caixa
Postal 285, CEP $35701-970$ Sete Lagoas, MG, Brasil. E-mail: alvaro.resende@embrapa.br (3)Universidade Federal de São João Del Rei,
Campus Sete Lagoas, Rodovia MG-424, Km 47, Caixa Postal 56, CEP 35701-970 Sete Lagoas, MG, Brasil. E-mail: otavio_prates@hotmail.com

Resumo - O objetivo deste trabalho foi avaliar os efeitos da adubação sobre os teores de $\mathrm{P}$ e K, em solo com fertilidade construída, e identificar as doses de N, P e K necessárias para obtenção de maior rentabilidade com a rotação entre soja e milho nesses solos. $\mathrm{O}$ experimento foi realizado durante três safras, em propriedade com alto investimento tecnológico, em Latossolo Vermelho-Amarelo argiloso de Cerrado, com elevada fertilidade. Utilizou-se o delineamento de blocos ao acaso, com parcelas subdividas e três repetições. Os tratamentos consistiram de 0,50,100 e 150\% das doses de fertilizantes NPK recomendadas na semeadura (parcelas) e das doses de $\mathrm{KCl}$ (soja) e $\mathrm{N}$ (milho) em cobertura (subparcelas). Mesmo após a colheita das três safras, os teores de P (Mehlich-1) se mantiveram inalterados no solo sem adubação. Além disso, não houve decréscimo na produtividade da soja na ausência de adubação. O milho, no entanto, foi mais sensível à redução de adubação, com o máximo retorno econômico obtido com $312 \mathrm{~kg} \mathrm{ha}^{-1}$ do adubo formulado 10-32-10, e $263 \mathrm{~kg} \mathrm{ha}^{-1}$ de ureia em cobertura. Solos com fertilidade construída demandam ajustes de manejo de adubação, para o uso eficiente dos fertilizantes em lavouras com alto investimento tecnológico.

Termos para indexação: adubação de sistema, economia de adubação, máxima eficiência econômica, plantio direto, uso eficiente de fertilizantes.

\section{Fertilization, grain yield and profitability of the rotation between soybean and corn in soil with improved fertility}

\begin{abstract}
The objective of this work was to evaluate the effects of fertilization on $\mathrm{P}$ and $\mathrm{K}$ levels in soil with improved fertility, and to identify $\mathrm{N}, \mathrm{P}$, and $\mathrm{K}$ doses needed to provide the greatest profitability in a rotation between soybean and corn in these soils. The experiment was carried out for three harvest seasons, in a farm with high technological investment, in a clayey Oxisol from Cerrado with high fertility. A randomized complete block design was used, in a split-plot arrangement with three replicates. Treatments consisted of $0,50,100$, and $150 \%$ of the recommended rates of NPK on sowing (plots), and of $\mathrm{KCl}$ (soybean) and $\mathrm{N}$ (corn) at topdressing. Even after three harvests, P (Mehlich-1) contents remained unchanged in the soil without fertilization. Moreover, soybean yield did not decrease in the absence of fertilization. However, corn was more sensible to the reduction of fertilization, with the maximum economic return obtained with $312 \mathrm{~kg} \mathrm{ha}^{-1}$ of the 10-32-10 fertilizer formulation, and of $263 \mathrm{~kg} \mathrm{ha}^{-1}$ urea at topdressing. Soils with improved fertility demand adjustments of fertilization management for the efficient use of fertilizers in crops with high technological investment.

Index terms: crop system fertilization, fertilizer saving, maximum economic efficiency, no tillage, efficient use of fertilizers.
\end{abstract}

\section{Introdução}

Solos de fertilidade construída são definidos como aqueles que, com o manejo ao longo do tempo, passam a apresentar condições físicas, biológicas e químicas adequadas para as culturas expressarem seu potencial produtivo (Kappes \& Zancanaro 2014).
Até a década de 1950, a agricultura brasileira dependia quase exclusivamente da fertilidade natural dos solos. Com a modernização da agricultura, práticas de correção da acidez e de adubação do solo contribuíram significativamente para a melhoria da fertilidade dos solos (Bernardi et al., 2002). Entretanto, o desafio atual quanto a esses solos de 
fertilidade construída é aumentar a eficiência de uso dos fertilizantes.

A ocorrência de talhões com elevados teores de $\mathrm{P}$ e $\mathrm{K}$, em áreas de produção comercial de grãos, tem sido comum no Cerrado, em razão do efeito residual de adubações prévias (Carneiro et al., 2009). No cerrado do Mato Grosso do Sul, por exemplo, Lourente et al. (2011) observaram teor de P (Mehlich-1) de $11 \mathrm{mg} \mathrm{dm}^{-3}$, à profundidade de $0-10 \mathrm{~cm}$, em Latossolo Vermelho distrófico típico com $700 \mathrm{~g} \mathrm{~kg}^{-1}$ de argila. No Piauí, Matias et al. (2009) relataram teores iguais a 57, 83 e $35 \mathrm{mg} \mathrm{dm}^{-3}$ de P, nas camadas 0-5, 5-10 e 10-20 $\mathrm{cm}$ de profundidade, respectivamente, em Latossolo Amarelo distrófico de textura média, sob plantio direto, enquanto o teor no cerrado nativo, às mesmas profundidades, foi de $0,3 \mathrm{mg} \mathrm{dm}^{-3}$. Na região Noroeste de Minas Gerais, Wilda (2014) relatou teores médios que variaram de 6 a $15 \mathrm{mg} \mathrm{dm}^{-3}$ de P, e de 164 a $212 \mathrm{mg} \mathrm{dm}^{-3}$ de K, com valores máximos de 12 a $39 \mathrm{mg} \mathrm{dm}^{-3}$ de $\mathrm{P}$ e de 199 a $280 \mathrm{mg} \mathrm{dm}^{-3}$ de $\mathrm{K}$, respectivamente.

Apesar de o nível de fertilidade do solo ser interpretado em muitos casos como alto ou muito alto, é comum que os agricultores continuem adubando com quantidades fixas de $\mathrm{N}, \mathrm{P}$ e $\mathrm{K}$, por temerem a redução de produtividade. Essa prática tem resultado em adubações desnecessárias ou superdimensionadas, com baixa eficiência de uso dos fertilizantes (Benites et al., 2010). É possível que lavouras conduzidas nesses solos possam manter inalterados os patamares produtivos mesmo com uso de menor quantidade de fertilizante, o que teria reflexos positivos sobre a rentabilidade dos empreendimentos.

Assim, é importante que se aproxime a pesquisa científica da atual tecnologia usada nas fazendas produtoras de grãos, na região do Cerrado, e que se entenda melhor o comportamento de $\mathrm{P}$ e $\mathrm{K}$ disponíveis em solos de fertilidade construída, em consequência da aplicação dos fertilizantes. Além desses aspectos, este trabalho aborda a adubação de sistemas, que estima a produtividade acumulada de grãos em função da quantidade total de N, P e K aplicadas, e apresenta a análise econômica da adubação.

O objetivo deste trabalho foi avaliar os efeitos da adubação sobre os teores de $\mathrm{P}$ e $\mathrm{K}$, em solo com fertilidade construída, e identificar as doses de N, P e $\mathrm{K}$ necessárias para obtenção da maior rentabilidade da rotação entre soja e milho nesses solos.

\section{Material e Métodos}

O estudo foi realizado entre 2010 e 2013, na Fazenda Decisão, Município de Unaí, MG, a 16²4'42"S e 47¹8'39"W, à altitude média de $992 \mathrm{~m}$. Segundo a classificação climática de Köppen-Geiger, a região apresenta clima do tipo Aw (clima de savanas), megatérmico - em que a temperatura média é superior a $18^{\circ} \mathrm{C}$, em todos os meses do ano -, com inverno seco e verão chuvoso (Sá Júnior, 2012). Os dados de temperatura e precipitação pluvial nos anos agrícolas 2010/2011, 2011/2012 e 2012/2013, em relação à média histórica, estão apresentados na Figura 1 (Banco..., 2014).

A área experimental foi estabelecida em talhão de produção comercial de grãos, cultivado por 15 anos em sistema plantio direto. $\mathrm{O}$ solo da área experimental foi classificado como Latossolo Vermelho-Amarelo distrófico típico argiloso (Santos et al., 2013), com $470 \mathrm{~g} \mathrm{~kg}^{-1}$ de argila. A caracterização química do solo (Silva, 2009) antes da implantação do experimento, na camada $0-20 \mathrm{~cm}$ de profundidade, mostrou: pH em água, 6,3; conteúdo de matéria orgânica, $32 \mathrm{~g} \mathrm{~kg}^{-1}$; teores disponíveis de $\mathrm{P}$ e $\mathrm{K}$ (Mehlich-1), de $12 \mathrm{e} 145 \mathrm{mg} \mathrm{dm}^{-3}$, respectivamente; e teores trocáveis de $\mathrm{Ca}, \mathrm{Mg}, \mathrm{Al}, \mathrm{H}+\mathrm{Al}$ e CTC, a pH 7,0, de 5,0, 1,1, $0,0,2,6,9,0 \mathrm{cmol}_{\mathrm{c}} \mathrm{dm}^{-3}$, respectivamente. A saturação por bases (V\%) foi $72 \%$. Essa condição de fertilidade pode ser considerada de adequada a alta, para a região do Cerrado (Sousa \& Lobato, 2004).

Durante o estudo, foram realizados três cultivos de verão, em condições de sequeiro, na sequência de rotação soja/milho/soja, tendo-se deixado o solo em pousio durante as entressafras.

Utilizou-se o delineamento experimental de blocos ao acaso, com parcelas subdivididas e três repetições. Nas parcelas, utilizaram-se quatro doses de fertilizantes NPK, na adubação de semeadura; e, nas subparcelas, quatro doses de $\mathrm{K}$ (no caso da soja) ou de $\mathrm{N}$ (no caso do milho), na adubação de cobertura.

Para a soja cultivada em 2010/2011, os tratamentos, consistiram das doses $0,143,303$ e $432 \mathrm{~kg} \mathrm{ha}^{-1}$ de NPK 10-32-10, nas parcelas, e de 0, 25, 50 e $75 \mathrm{~kg} \mathrm{ha}^{-1}$ de $\mathrm{KCl}$ em cobertura (estádio V3), nas subparcelas. Para o milho, cultivado em 2011/2012, os tratamentos, consistiram das doses $0,184,359$ e $536 \mathrm{~kg} \mathrm{ha}^{-1}$ de NPK 10-32-10, nas parcelas, e de $0,175,350$ e $525 \mathrm{~kg} \mathrm{ha}^{-1}$ de ureia, com inibidor de urease, em cobertura (estádio V4) nas subparcelas. Para a soja cultivada em 
2012/2013, os tratamentos consistiram das doses 0 , 150,221 e $280 \mathrm{~kg} \mathrm{ha}^{-1}$ de MAP (fosfato monoamônico, com $54 \%$ de $\mathrm{P}_{2} \mathrm{O}_{5}$ e $10 \%$ de $\mathrm{N}$ ), nas parcelas, e de 0,75 , 150 e $225 \mathrm{~kg} \mathrm{ha}^{-1}$ de $\mathrm{KCl}$ em cobertura (estádio V1) nas subparcelas. Considerou-se como testemunha o manejo da adubação normalmente utilizado pelo agricultor, correspondente à terceira dose dos tratamentos aplicados no presente estudo, tanto nas adubações de semeadura quanto nas de cobertura. Portanto, as doses das adubações incluíram quantidades de fertilizantes abaixo, iguais e acima das empregadas pelo agricultor. As adubações de semeadura foram realizadas no sulco, via semeadora, e as aplicações em cobertura foram feitas manualmente, com filete de adubo nas entrelinhas.

As parcelas experimentais corresponderam a oito linhas de $40 \mathrm{~m}$ de comprimento. Tanto a soja como o milho foram semeados com $0,5 \mathrm{~m}$ entre as linhas, o que resultou em parcelas com $160 \mathrm{~m}^{2}$. As subparcelas foram compostas pela divisão das linhas da parcela em quatro, com $10 \mathrm{~m}$ de comprimento cada $\left(40 \mathrm{~m}^{2}\right)$.

Na primeira safra utilizou-se a soja 'RA 518 RR', precoce, com hábito de crescimento indeterminado, semeada em 23/11/2010, com 380 mil sementes por hectare. Na segunda safra, o milho híbrido simples DKB 175 PRO foi semeado com 68 mil sementes por hectare, em 27/10/2011. Na terceira safra, a soja 'Riber 7211 RR', precoce, com hábito de crescimento indeterminado foi semeada com população de $280 \mathrm{mil}$ sementes por hectare, em 13/12/2012. As sementes da soja não receberam inoculação de bactérias fixadoras de nitrogênio, pois estas já haviam sido utilizadas em cultivos prévios ao experimento.

Amostragens de solo e de folhas da soja foram realizadas tanto em 2010/2011 como em 2012/2013, durante o estádio R2, para avaliar a fertilidade e o estado nutricional das plantas, no período de maior demanda por nutrientes pela cultura. Nas amostragens de solo, coletaram-se nove amostras simples, da área central das subparcelas, três das linhas e seis das entrelinhas, à profundidade $0-20 \mathrm{~cm}$. Nas amostragens foliares, o $3^{\circ}$ trifólio (com pecíolo) a partir do ápice de cada planta foi coletado de 20 plantas por subparcela (Boaretto et al., 2009).

As amostragens de solo e folha, no cultivo do milho, foram realizadas durante o florescimento feminino. A coleta das amostras de solo seguiu o mesmo critério da amostragem feita nos cultivos da soja. A amostragem foliar consistiu da coleta de folhas inteiras, com nervura, localizadas abaixo e em posição oposta à espiga, de 15 plantas da área central de cada subparcela. As amostras de solo foram submetidas à análise dos teores de $\mathrm{P}$ e $\mathrm{K}$; e as de folhas e grãos, à análise de N, P e K (Silva, 2009).

A colheita foi realizada manualmente, na área útil central das subparcelas, com $6 \mathrm{~m}^{2}$ (três linhas de $4 \mathrm{~m}$ de

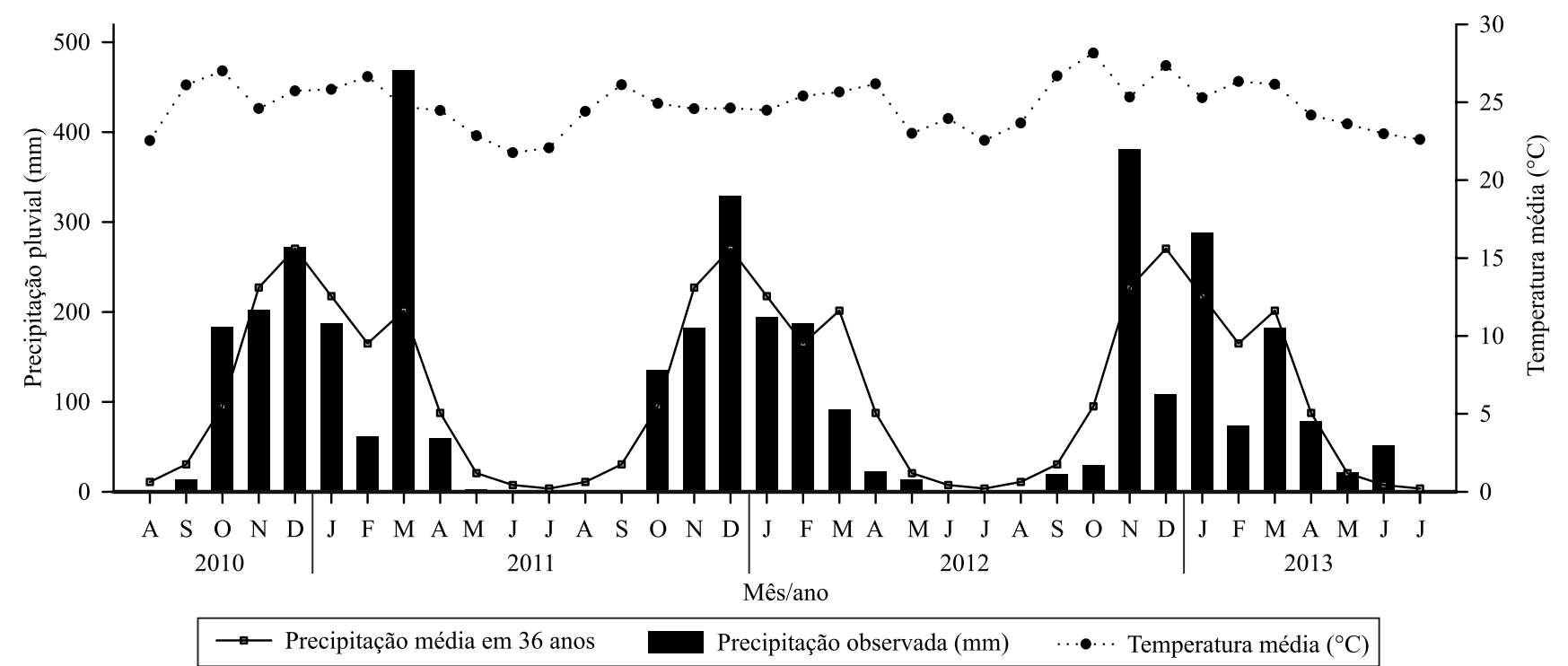

Figura 1. Precipitação pluvial e temperatura média mensal observadas na Fazenda Decisão, Unaí, MG, entre agosto de 2010 e julho de 2013, e média histórica da precipitação pluvial em 36 anos (1978-2014). Fonte: Banco... (2014). 
comprimento). Determinaram-se a umidade e a massa de grãos, tendo-se corrigido a produtividade para $13 \%$ de umidade, em ambas as culturas.

Os dados de produtividade foram submetidos à análise de variância, a 5\% de probabilidade, com o uso do sistema Sisvar (Ferreira, 2011). No caso de efeito significativo dos tratamentos, foram geradas equações de regressão para estimar a produtividade em função das doses dos fertilizantes aplicados.

Um modelo de regressão múltipla foi estabelecido para avaliar a produtividade acumulada de soja e milho, em função das quantidades totais de $\mathrm{N}, \mathrm{P}_{2} \mathrm{O}_{5}$ e $\mathrm{K}_{2} \mathrm{O}$ aplicadas nas três safras. A equação de regressão múltipla foi elaborada, tendo-se utilizado a função $\mathrm{lm}$, do pacote Stats, do programa R (R Foundation for Statistical Computing, Viena, Áustria). A abordagem multivariada é pertinente neste estudo, pois os tratamentos não permitem isolar o efeito de cada nutriente; assim, a produtividade obtida reflete o efeito conjunto das diferentes proporções de $\mathrm{N}, \mathrm{P}_{2} \mathrm{O}_{5}$ e $\mathrm{K}_{2} \mathrm{O}$.

A avaliação econômica dos resultados foi realizada a partir dos indicadores de rentabilidade: produtividade, custo da adubação, receita bruta, ponto de equilíbrio e receita líquida. $O$ custo operacional total da adubação foi obtido pela soma dos custos de aquisição dos fertilizantes, operação mecanizada e encargos financeiros para capital de custeio. Os preços dos fertilizantes tomados como referência - em reais por tonelada, cotados no mês de abril (Preços..., 2013) foram de: 1.110,00, para o formulado N-P-K 10-32-10; $1.830,46$, para a ureia; $1.774,20$, para o KCl; e 1.602,00, para o MAP. O custo da aplicação de fertilizantes foi de $\mathrm{R} \$ 35,34$ ha $^{-1}$ (Custo..., 2013), e a taxa de juros do custeio agrícola de 5,5\% ao ano (Agronegócio, 2014). A receita bruta foi calculada a partir do valor dos grãos, em reais, nas cotações de 10 de abril de 2013: 27,01, para a saca de $60 \mathrm{~kg}$ de milho; e 55,02, para a saca de soja (Preços..., 2013). A receita líquida foi obtida pela diferença entre receita bruta e custo operacional total da adubação. O ponto de equilíbrio $\left(\mathrm{kg} \mathrm{ha}^{-1}\right)$ foi calculado pela relação entre o custo operacional total da adubação $\left(\mathrm{R} \$\right.$ ha $\left.^{-1}\right)$ e a diferença entre o preço de venda e custo variável unitário $\left(\mathrm{R} \$ \mathrm{~kg}^{-1}\right)$. Esse índice corresponde à quantidade de grãos em que a receita bruta se iguala ao custo operacional total da adubação. Como referência monetária, o valor do dólar americano para compra em 10 de abril de 2013 era de $\mathrm{R} \$ 1,976$.

\section{Resultados e Discussão}

Não houve interação significativa entre as adubações de semeadura e de cobertura, quanto aos teores disponíveis de $\mathrm{P}$ no solo, em nenhuma das safras avaliadas no experimento. Nos dois primeiros anos, os tratamentos também não tiveram efeito sobre teores de P. Porém, no terceiro ano, observou-se efeito linear dos níveis de adubação de semeadura sobre os teores de $\mathrm{P}$ no solo (Tabela 1).

Mesmo após três cultivos sucessivos, o fator capacidade do solo, ou poder tampão de fósforo no solo, foi capaz de manter o teor inicial de P disponível. Em solos argilosos, e particularmente nos mais intemperizados, como o do presente estudo, a relação $\mathrm{Q} / \mathrm{I}$ entre a quantidade de $\mathrm{P}$ na fase sólida do solo (Q) e na solução (I) é normalmente alta. Assim, à medida que a concentração na solução diminui, em razão da absorção pelas culturas, ocorre a liberação do $\mathrm{P}$ adsorvido aos coloides para a solução, a fim de manter o equilíbrio (Novais et al., 2007).

Para o K, o poder tampão do solo foi menor, tendose observado variações maiores nos teores disponíveis ao longo dos cultivos, em consequência das adubações potássicas de cobertura nas safras de soja (Tabela 1). Mesmo nos tratamentos com as maiores doses de $\mathrm{K}_{2} \mathrm{O}$, houve redução significativa do teor do elemento no solo à época do florescimento, em comparação com o teor disponível antes da condução do experimento $\left(145 \mathrm{mg} \mathrm{dm}^{-3}\right)$. Essa redução pode ser explicada pela intensa extração do nutriente pelas culturas da soja e, principalmente, do milho. No entanto, trata-se de uma depleção temporária da disponibilidade do nutriente (Costa et al., 2009), pois grande proporção do que é absorvido acumula-se nas partes vegetativas das plantas e é liberada para o solo após a decomposição dos resíduos culturais. Além disso, o íon $\mathrm{K}^{+}$encontrase na planta predominantemente como cátion livre, que pode ser facilmente lixiviado dos tecidos vegetais que cobrem o solo (Marschner, 2012). Portanto, a ciclagem do elemento no sistema solo-planta pode explicar as variações observadas na análise do solo, mesmo ao se considerar a quantidade exportada nos grãos.

Os teores foliares de P e K (Tabela 1) estiveram dentro da faixa de suficiência nutricional relatada por Cantarutti et al. (2007) para soja e o milho. No entanto, os teores foliares de $\mathrm{N}$ da soja estiveram acima da faixa de suficiência; enquanto, no milho, estiveram ligeiramente abaixo do teor de referência $\left(30 \mathrm{~g} \mathrm{~kg}^{-1}\right)$. 
A soja não respondeu às adubações de semeadura ou de cobertura, em nenhuma das safras (Tabela 2). A produtividade média de soja obtida no experimento foi de $3.466 \mathrm{~kg} \mathrm{ha}^{-1}$, em 2010/2011, e $3.485 \mathrm{~kg} \mathrm{ha}^{-1} \mathrm{em}$ 2012/2013. É importante levar em consideração o fato de que o experimento foi realizado em condições de sequeiro, e que a quantidade de chuvas, em algumas fases fenológicas importantes para a cultura, esteve abaixo das médias históricas na região (Figura 1), o que pode ter contribuído para a falta de resposta à adubação e para a produtividade relativamente baixa da soja. Brevilieri (2012) também não encontrou respostas da soja ao aumento das doses de fertilizantes fosfatados, aplicadas a Latossolo argiloso cultivado sob plantio direto por 16 anos, em Dourados, MS. O autor atribuiu o resultado à boa fertilidade já existente naquela área, 0 que também ocorreu no presente trabalho. Além disso, a cultura da soja é normalmente menos responsiva ao manejo da fertilidade do solo do que a do milho (Wendling et al., 2008).
Nesses casos de elevada fertilidade do solo, a adubação de manutenção com quantidades que apenas reponham a exportação nos grãos constitui o manejo mais racional, uma vez que os nutrientes aplicados e não absorvidos pelas plantas podem ficar sujeitos a processos de perdas no sistema (Moreira et al., 2006; Werle et al., 2008).

A produtividade do milho (safra 2011/2012), no entanto, respondeu tanto à adubação de semeadura como à de cobertura (Figura 2), o que confirma a maior responsividade da espécie à adubação. Wendling et al. (2008), ao estudar a adubação potássica para trigo, milho e soja sob sistema plantio direto, no Paraguai, também relataram maior resposta do milho à adubação. Assim, para sistemas que envolvam rotação soja/milho, a manutenção de níveis de fertilidade que atendam aos requerimentos nutricionais tanto da soja como do milho é necessária, para evitar perda do potencial produtivo do sistema como um todo.

Tabela 1. Disponibilidade de $\mathrm{P}$ e $\mathrm{K}$ no solo na camada 0-20 cm, teores foliares de $\mathrm{N}, \mathrm{P}$ e $\mathrm{K}$ e quantidades exportadas dos nutrientes nos grãos $\left(\mathrm{kg} \mathrm{ha}^{-1}\right)$, ao longo de três safras (soja/milho/soja), em função do fornecimento de diferentes quantidades de fertilizantes nas adubações de semeadura e de cobertura, em Latossolo com fertilidade construída.

\begin{tabular}{|c|c|c|c|c|c|c|c|c|c|c|c|c|c|c|c|c|c|}
\hline \multirow{3}{*}{$\begin{array}{l}\text { Adubação de } \\
\text { semeadura } \\
\left(\mathrm{kg} \mathrm{ha}^{-1}\right)\end{array}$} & \multicolumn{2}{|c|}{ Solo } & \multicolumn{3}{|c|}{ Folha } & \multicolumn{3}{|c|}{ Exportação } & \multirow{2}{*}{$\begin{array}{l}\text { Adubação } \\
\text { cobertura }^{(2)}\end{array}$} & \multicolumn{2}{|c|}{ Solo } & \multicolumn{3}{|c|}{ Folha } & \multicolumn{3}{|c|}{ Exportação } \\
\hline & $\mathrm{P}$ & K & $\mathrm{N}$ & $\mathrm{P}$ & K & $\mathrm{N}$ & $\mathrm{P}$ & $\mathrm{K}$ & & $\mathrm{P}$ & K & $\mathrm{N}$ & $\mathrm{P}$ & K & $\mathrm{N}$ & $\mathrm{P}$ & $\mathrm{K}$ \\
\hline & \multicolumn{2}{|c|}{$--\left(\mathrm{mg} \mathrm{dm}^{-3}\right)--$} & \multicolumn{3}{|c|}{--------( $\left(\mathrm{g} \mathrm{kg}^{-1}\right)$-------- } & \multicolumn{3}{|c|}{------(kg ha'-1)----- } & $\left(\mathrm{kg} \mathrm{ha}^{-1}\right)$ & \multicolumn{2}{|c|}{$--\left(\mathrm{mg} \mathrm{dm}^{-3}\right)--$} & \multicolumn{3}{|c|}{--------( $\left(\mathrm{g} \mathrm{kg}^{-1}\right)$------- } & \multicolumn{3}{|c|}{------(kg ha-1)------- } \\
\hline & \multicolumn{17}{|c|}{ Soja, safra $2010 / 2011$} \\
\hline 0 & 18,7 & 84,2 & 77 & 4,1 & 16,8 & 213 & 21 & 52 & 0 & 20,0 & 64,5 & 73 & 4,2 & 17,7 & 211 & 20 & 53 \\
\hline 143 & 27,9 & 82,2 & 71 & 4,3 & 17,7 & 213 & 20 & 50 & 25 & 19,6 & 76,4 & 73 & 4,2 & 17,5 & 205 & 19 & 53 \\
\hline 303 & 18,9 & 86,6 & 68 & 4,2 & 17,5 & 205 & 19 & 55 & 50 & 23,4 & 82,4 & 70 & 4,1 & 17,0 & 211 & 19 & 55 \\
\hline 432 & 19,5 & 72,4 & 69 & 4,1 & 17,8 & 208 & 19 & 61 & 75 & 22,0 & 102,0 & 69 & 4,2 & 17,5 & 210 & 20 & 56 \\
\hline $\mathrm{CV}(\%)$ & 50,4 & 24,3 & 3,2 & 1,6 & 4,5 & 7,0 & 8,9 & 7,8 & - & 37,2 & 15,9 & 4,6 & 4,2 & 3,8 & 5,7 & 10,3 & 6,4 \\
\hline Regressão & ns & ns & $\mathrm{L}^{* *}$ & $\mathrm{Q}^{* *}$ & ns & ns & ns & $\mathrm{Q}^{*}$ & - & ns & $\mathrm{L}^{* *}$ & $\mathrm{~L}^{* *}$ & ns & ns & ns & ns & $\mathrm{L}^{*}$ \\
\hline & \multicolumn{17}{|c|}{ Milho, safra 2011/2012 } \\
\hline 0 & 11,8 & 64,8 & 28 & 2,4 & 17,3 & 146 & 20 & 41 & 0 & 15,6 & 74,5 & 26 & 2,6 & 18,6 & 157 & 22 & 48 \\
\hline 184 & 15,3 & 60,0 & 29 & 2,7 & 17,7 & 180 & 24 & 51 & 175 & 18,8 & 64,6 & 28 & 2,9 & 17,6 & 175 & 23 & 50 \\
\hline 359 & 24,2 & 69,9 & 28 & 3,1 & 19,2 & 184 & 25 & 52 & 350 & 24,4 & 64,8 & 29 & 2,9 & 19,3 & 183 & 24 & 50 \\
\hline 536 & 23,0 & 66,4 & 29 & 3,3 & 19,6 & 188 & 25 & 53 & 525 & 15,4 & 57,1 & 30 & 3,0 & 18,3 & 182 & 24 & 51 \\
\hline$\overline{\mathrm{CV}}(\%)$ & 57,8 & 7,7 & 4,5 & 10,1 & 5,6 & 10,9 & 12,3 & 9,9 & - & 44,4 & 12,8 & 5,0 & 10,8 & 11,2 & 8,0 & 9,2 & 7,9 \\
\hline \multirow[t]{2}{*}{$\underline{\text { Regressão }}$} & ns & ns & ns & $\mathrm{L}^{* *}$ & $\mathrm{~L}^{*}$ & $\mathrm{Q}^{*}$ & $\mathrm{~L}^{*}$ & $\mathrm{~L}^{* *}$ & - & $\mathrm{Q}^{*}$ & $\mathrm{~L}^{* *}$ & $\mathrm{~L}^{*}$ & $\mathrm{~L}^{*}$ & ns & $\mathrm{Q}^{*}$ & ns & ns \\
\hline & \multicolumn{17}{|c|}{ Soja, safra $2012 / 2013$} \\
\hline 0 & 17 & 135 & 54 & 2,9 & 25,8 & 210 & 19 & 58 & 0 & 23 & 106 & 58 & 3,3 & 26,1 & 224 & 22 & 63 \\
\hline 150 & 22 & 128 & 58 & 3,2 & 26,1 & 234 & 23 & 64 & 150 & 28 & 136 & 57 & 3,2 & 25,5 & 225 & 21 & 62 \\
\hline 221 & 36 & 140 & 58 & 3,4 & 25,5 & 224 & 21 & 63 & 221 & 26 & 143 & 57 & 3,2 & 26,6 & 225 & 22 & 64 \\
\hline 280 & 35 & 149 & 59 & 3,5 & 26,8 & 231 & 23 & 69 & 280 & 35 & 167 & 57 & 3,3 & 26,1 & 226 & 22 & 65 \\
\hline CV (\%) & 45,7 & 23,4 & 3,4 & 12,2 & 5,0 & 6,7 & 6,9 & 11,1 & - & 37,8 & 16,4 & 3,6 & 6,9 & 10,0 & 6,4 & 7,9 & 9,3 \\
\hline Regressão & $\mathrm{L}^{*}$ & ns & $\mathrm{L}^{*}$ & $\mathrm{~L}^{*}$ & ns & $\mathrm{L}^{*}$ & $\mathrm{~L}^{* *}$ & $\mathrm{~L}^{* *}$ & - & ns & $\mathrm{L}^{* *}$ & ns & ns & ns & ns & ns & ns \\
\hline
\end{tabular}


A resposta do milho à adubação de semeadura ajustou-se a um modelo quadrático, enquanto a resposta à ureia foi linear (Figura 2). A baixa intensidade da resposta à ureia deveu-se, provavelmente, ao elevado teor de matéria orgânica no solo $\left(32 \mathrm{~g} \mathrm{~kg}^{-1}\right)$ e ao fato de a cultura do milho ter sido plantada após o cultivo da soja. Lange et al. (2008) não observaram resposta do milho à adubação nitrogenada em cobertura, após dois anos de cultivo de soja em plantio direto.

A ausência de resposta da soja e a baixa resposta do milho à adubação de cobertura são indícios de que o solo, de fato, apresentava grande reserva de nutrientes, e de que é possível diminuir a quantidade de fertilizantes aplicadas no solo avaliado. Portanto, a adubação com quantidades fixas de $\mathrm{N}, \mathrm{P}$ e $\mathrm{K}$ não parece adequada para o manejo do sistema de produção de soja e milho em solos com esse padrão de fertilidade.

Com relação à produção acumulada nas três safras, observou-se incremento da produtividade com o aumento da quantidade de adubo aplicada (Tabela 2). Sem o aporte de nutrientes, o rendimento total de grãos das três safras estimado apartir do modelo de regressão foi de $16.662 \mathrm{~kg} \mathrm{ha}^{-1}$; no entanto, quando foram adicionados ao sistema 359,453 e $277 \mathrm{~kg} \mathrm{ha}^{-1} \mathrm{de}$
$\mathrm{N}, \mathrm{P}_{2} \mathrm{O}_{5}$ e $\mathrm{K}_{2} \mathrm{O}$, respectivamente, o rendimento máximo subiu para $19.754 \mathrm{~kg} \mathrm{ha}^{-1}$.

O nitrogênio foi o nutriente com o maior coeficiente angular no modelo de regressão linear múltipla; enquanto o do potássio foi negativo (Tabela 2). É importante ressaltar, entretanto, que as quantidades de $\mathrm{N}$ e K fornecidas no experimento apresentaram relação entre os nutrientes de aproximadamente 4:3, em todos os tratamentos (Tabela 2). Portanto, o coeficiente negativo obtido para o $\mathrm{K}$ no modelo não significa, necessariamente, que a adubação com o nutriente seja dispensável, ou que ele interfira negativamente na produtividade do sistema, mas sim que a relação existente entre os dois nutrientes influencia os valores dos coeficientes.

O maior coeficiente de determinação obtido com o modelo de regressão múltipla, na comparação com os obtidos com modelos de regressão simples, mostra claramente que não é possível atribuir o incremento da produtividade acumulada pela adubação a um nutriente isoladamente, neste tipo de experimento (Tabela 2). As diferentes proporções de $\mathrm{N}, \mathrm{P}_{2} \mathrm{O}_{5}$ e $\mathrm{K}_{2} \mathrm{O}$ tiveram efeito aditivo, mas não interativo, sobre a produtividade do sistema.

Tabela 2. Produtividade acumulada de soja e milho, durante as três safras avaliadas, em função do somatório das doses de $\mathrm{N}, \mathrm{P}_{2} \mathrm{O}_{5}$ e $\mathrm{K}_{2} \mathrm{O}$ fornecidas nas adubações em cada tratamento, e valores estimados de produtividade pelo modelo de regressão linear múltipla.

\begin{tabular}{|c|c|c|c|c|c|c|c|c|}
\hline \multirow[t]{2}{*}{ Tratamento } & \multicolumn{3}{|c|}{ Total aplicado $\left(\mathrm{kg} \mathrm{ha}^{-1}\right)$} & \multicolumn{4}{|c|}{ Produtividade de grãos $\left(\mathrm{kg} \mathrm{ha}^{-1}\right)$} & \multirow{2}{*}{$\begin{array}{c}\text { Produtividade }{ }^{(1)} \\
\left(\mathrm{kg} \mathrm{ha}^{-1}\right)\end{array}$} \\
\hline & $\mathrm{N}$ & $\mathrm{P}_{2} \mathrm{O}_{5}$ & $\mathrm{~K}_{2} \mathrm{O}$ & Soja $2010 / 11$ & Milho 2011/12 & Soja 2012/13 & Total & \\
\hline$\overline{1}$ & 0 & 0 & 0 & 3.762 & 9.729 & 3.334 & 16.825 & 16.662 \\
\hline 2 & 78 & 0 & 60 & 3.372 & 10.238 & 3.176 & 16.786 & 16.937 \\
\hline 3 & 156 & 0 & 120 & 3.568 & 10.778 & 3.241 & 17.587 & 17.212 \\
\hline 4 & 234 & 0 & 180 & 3.487 & 10.287 & 3.304 & 17.078 & 17.487 \\
\hline 5 & 47 & 183 & 32 & 3.437 & 11.638 & 3.595 & 18.670 & 18.774 \\
\hline 6 & 125 & 183 & 92 & 3.609 & 12.348 & 3.661 & 19.618 & 19.049 \\
\hline 7 & 203 & 183 & 152 & 3.486 & 12.215 & 3.648 & 19.349 & 19.324 \\
\hline 8 & 281 & 183 & 212 & 3.524 & 12.467 & 3.603 & 19.594 & 19.599 \\
\hline 9 & 88 & 325 & 66 & 3.343 & 11.615 & 3.470 & 18.428 & 18.903 \\
\hline 10 & 166 & 325 & 126 & 3.172 & 12.416 & 3.324 & 18.912 & 19.178 \\
\hline 11 & 244 & 325 & 186 & 3.345 & 12.175 & 3.490 & 19.010 & 19.453 \\
\hline 12 & 322 & 325 & 246 & 3.557 & 12.711 & 3.708 & 19.976 & 19.728 \\
\hline 13 & 125 & 453 & 97 & 3.454 & 11.897 & 3.512 & 18.863 & 18.928 \\
\hline 14 & 203 & 453 & 157 & 3.425 & 12.385 & 3.678 & 19.488 & 19.203 \\
\hline 15 & 281 & 453 & 217 & 3.546 & 12.963 & 3.592 & 20.101 & 19.479 \\
\hline 16 & 359 & 453 & 277 & 3.373 & 12.594 & 3.430 & 19.397 & 19.754 \\
\hline
\end{tabular}

(1)Produtividade acumulada estimada pelo modelo de regressão linear múltipla (RLM). Modelo RLM com todos os nutrientes: $\mathrm{Y}=16.661+242,9 * * \mathrm{~N}+$ $10,37 * * \mathrm{P}_{2} \mathrm{O}_{5}-322,0 * * \mathrm{~K}_{2} \mathrm{O}\left(\mathrm{R}^{2}=0,90\right)$. Regressão linear simples com cada nutriente $\left(\mathrm{N}, \mathrm{P}_{2} \mathrm{O}_{5}\right.$ e $\left.\mathrm{K}_{2} \mathrm{O}\right)$ individualmente: $\mathrm{Y}=17.536+6,51 * \mathrm{~N}\left(\mathrm{R}^{2}=0,37\right)$, $\mathrm{Y}=17.238+6,80 * * \mathrm{P}_{2} \mathrm{O}_{5}\left(\mathrm{R}^{2}=0,62\right)$ e $\mathrm{Y}=17.561+8,41 * \mathrm{~K}_{2} \mathrm{O}\left(\mathrm{R}^{2}=0,36\right)$. 

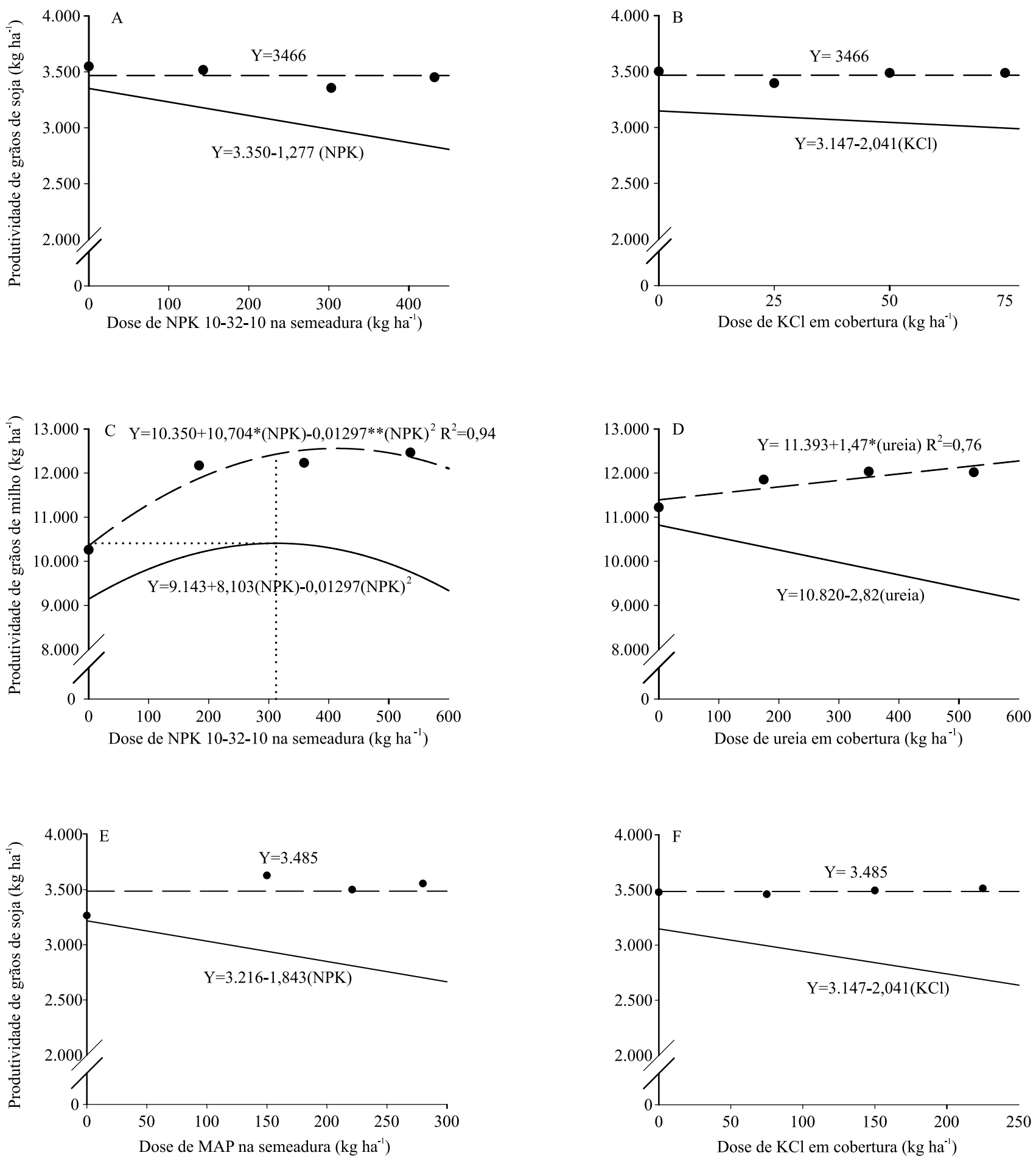

Figura 2. Produtividade bruta e produtividade líquida da soja e do milho, em função das doses de fertilizantes utilizadas na semeadura e na cobertura, em Latossolo de fertilidade construída, nas safras 2010/2011, 2011/2012 e 2012/2013. Em A, C e E, considerou-se a aplicação da dose média da adubação de cobertura: 37,5, 263 e $112,5 \mathrm{~kg} \mathrm{ha}^{-1} \mathrm{de} \mathrm{KCl}$, ureia e $\mathrm{KCl}$, respectivamente; e em B, D e F, considerou-se a aplicação da dose média da adubação de semeadura: 219,5 e $270 \mathrm{~kg}^{-1} \mathrm{do}^{-1}$ formulado NPK 10-32-10, e 162,75 $\mathrm{kg} \mathrm{ha}^{-1}$ de MAP, respectivamente. A linha pontilhada na vertical em C representa a dose de máxima eficiência econômica. 
O comportamento linear crescente da produção acumulada nas três safras indica que é possível aumentar a eficiência de uso dos fertilizantes com a adoção da prática da adubação de sistemas. Nesse tipo de manejo da adubação, a recomendação de fertilizantes deixa de ser realizada isoladamente para uma cultura, e passa-se a considerar o sistema como um todo (Oliveira Júnior et al., 2010). Alguns autores sugerem que culturas mais responsivas como a do milho devem ser adubadas mais intensamente, enquanto as menos responsivas, como a da soja, podem ser cultivadas apenas com a adubação de arranque e com a adubação residual da cultura anterior (Benites et al., 2010; Altmann, 2012). Os resultados do presente trabalho corroboram essa possibilidade.
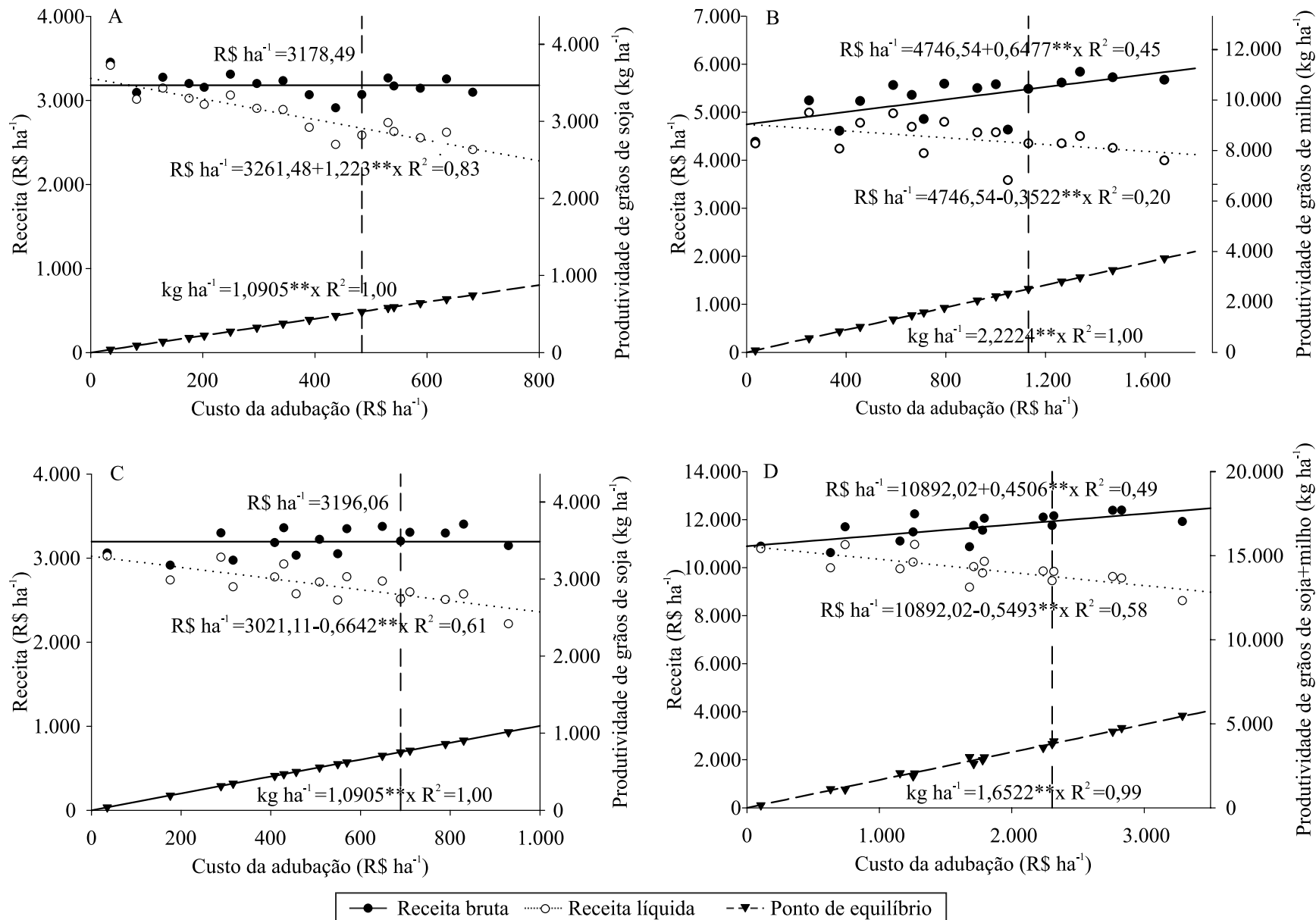

Figura 3. Indicadores de rentabilidade da aplicação de fertilizantes às culturas de soja (A e C) e milho (B), e para produtividade acumulada (D) das três safras (soja/milho/soja), em Latossolo de fertilidade construída. A linha tracejada na vertical representa o manejo da adubação no tratamento referência (manejo utilizado na fazenda).

Pesq. agropec. bras., Brasília, v.50, n.9, p.769-778, set. 2015

DOI: 10.1590/S0100-204X2015000900005
A análise de rentabilidade evidenciou que, uma vez que a soja não respondeu à aplicação de fertilizantes, a produtividade (Figura 2) e receita líquidas (Figura 3) diminuiram com a adubação.

Como não houve interação entre a adubação de semeadura e a de cobertura, sobre a produtividade do milho, considerou-se a dose média da adubação de cobertura (263 kg ha-1 de ureia) na análise econômica da adubação de semeadura. Do mesmo modo, na avaliação econômica da adubação de cobertura, considerou-se a dose média da adubação de semeadura $\left(270 \mathrm{~kg} \mathrm{ha}^{-1} \mathrm{de}\right.$ 10-32-10). A resposta do milho expressou claramente a lei dos rendimentos decrescentes: a fertilização aumentou a produtividade líquida no início; em seguida, no entanto, esta atingiu um valor máximo e decresceu com o aumento nas doses (Figura $2 \mathrm{C}$ ). 
Para o milho, a máxima produtividade física estimada foi $12.558 \mathrm{~kg} \mathrm{ha}^{-1}$, com a aplicação de $412 \mathrm{~kg} \mathrm{ha}^{-1} \mathrm{de}$ 10-32-10 na adubação de semeadura. Adose de máxima eficiência econômica da adubação de semeadura foi estimada em $99 \%$ da máxima produtividade física $\left(12.428 \mathrm{~kg} \mathrm{ha}^{-1}\right)$, obtida com a aplicação de $312 \mathrm{~kg} \mathrm{ha}^{-1}$ de adubo (Figura $2 \mathrm{C}$ ).

$\mathrm{O}$ coeficiente angular da produtividade bruta em relação à adubação de cobertura do milho foi de apenas 1,47 (Figura 2 D). Assim, para que ela seja viável economicamente, o preço de $1 \mathrm{~kg}$ de ureia deveria ser menor que 1,47 vezes o preço de $1 \mathrm{~kg}$ de milho. No entanto, de acordo com as cotações levantadas, a razão entre o preço da ureia e o preço do milho foi de 3,20. Logo, considerando-se apenas o aspecto econômico, a adubação nitrogenada em cobertura resultou em decréscimo da produtividade líquida do milho (Figura 2 D). Todavia, há que se levar em conta que o fornecimento de $\mathrm{N}$ é necessário para a sustentabilidade do sistema de produção, pois apenas os resíduos da soja não fornecem a quantidade de $\mathrm{N}$ necessária à demanda do milho. Alves et al. (2006) quantificaram um saldo de apenas $10 \mathrm{~kg} \mathrm{ha}^{-1}$ no balanço de $\mathrm{N}$, para a média de dois cultivos de soja com produtividade de $3.200 \mathrm{~kg} \mathrm{ha}^{-1}$ de grãos.

A dose de fertilizante normalmente utilizada na fazenda para a adubação de semeadura do milho (359 $\mathrm{kg} \mathrm{ha}^{-1}$ ) pode ser reduzida em $47 \mathrm{~kg} \mathrm{ha}^{-1}$ (13\%), uma vez que a dose de máxima eficiência econômica obtida no trabalho foi de $312 \mathrm{~kg} \mathrm{ha}^{-1}$. Além disso, se for considerada a dose média de ureia aplicada no presente trabalho, a adubação de cobertura pode ser reduzida de 350 para $263 \mathrm{~kg} \mathrm{ha}^{-1}$, ou em $25 \%$.

A produtividade, a receita bruta, a receita líquida e o custo operacional total da adubação, bem como o ponto de equilíbrio dos 16 tratamentos, estão apresentados na Figura 3. A ausência de resposta da soja à adubação contribuiu para redução da receita líquida do sistema, com o maior investimento em fertilizantes. Além disso, o aumento de produtividade do milho, obtido com a fertilização, não foi suficiente para aumentar a receita líquida do sistema como um todo (Figura 3 D), uma vez que o custo marginal dos fertilizantes foi maior do que a receita marginal proporcionada por eles. Esses resultados indicam a necessidade de se reavaliar o manejo da adubação, em solos com fertilidade construída, para conciliar o uso mais eficiente de fertilizantes com maior lucratividade para o produtor.

\section{Conclusões}

1. Mesmo após a colheita de três safras de grãos sem o uso de fertilizantes, o Latossolo de fertilidade construída é capaz de manter inalterados os teores de $\mathrm{P}$ disponível no solo.

2. O milho é mais sensível às fertilizações do que a soja e responde economicamente à adubação, mesmo nas condições de alta fertilidade do solo avaliadas.

3. O aumento da produtividade total de grãos, em função da adubação do sistema avaliado nas três safras, não é suficiente para compensar os custos dessa prática no Latossolo de fertilidade construída avaliado.

4. O monitoramento da disponibilidade de nutrientes e a adequação da fertilização são indispensáveis para aumentar a eficiência técnica e econômica da fertilização, em solos de fertilidade construída.

\section{Agradecimentos}

À Fundação de Amparo à Pesquisa do Estado de Minas Gerais (Fapemig), pelo apoio financeiro (processo APQ 01424/09) e concessão de bolsas (convênio 5.174/11 e processo CAG 22.011/13); e à Fazenda Decisão, pela seção de área e apoio logístico.

\section{Referências}

AGRONEGÓCIO: crédito: custeio rural: custeio agropecuário: custeio agrícola. Brasília: Banco do Brasil, [2014]. Disponível em: $<$ http://www.bb.com.br/portalbb/page100,8623,8649,0,0,1,1.bb? codigoNoticia $=83 \&$ codigoMenu $=18709 \&$ codigoRet $=11755 \&$ bre ad=1_1>. Acesso em: 25 jan. 2014.

ALTMANN, N. Adubação de sistemas integrados de produção em plantio direto: resultados práticos no Cerrado. Informações Agronômicas, n.140, p.1-8, 2012.

ALVES, B.J.R.; ZOTARELLI, L.; FERNANDES, F.M.; HECKLER, J.C.; MACEDO, R.A.T. de; BODDEY, R.M.; JANTALIA, C.P.; URQUIAGA, S. Fixação biológica de nitrogênio e fertilizantes nitrogenados no balanço de nitrogênio em soja, milho e algodão. Pesquisa Agropecuária Brasileira, v.41, p.449-456, 2006. DOI: 10.1590/S0100-204X2006000300011.

BANCO de dados meteorológicos para ensino e pesquisa. Série histórica. Dados mensais. Unaí (MG). [2014]. Brasília: Instituto Nacional de Meteorologia, [2014]. Disponível em: <http://www. inmet.gov.br/portal/index.php?r=bdmep/bdmep $>$. Acesso em: 17 set. 2014.

BENITES, V. de M.; POLIDORO, J.C.; RESENDE, A.V. Oportunidades para a inovação tecnológica no setor de fertilizantes no Brasil. Boletim Informativo da SBCS, v.35, p.18-21, 2010. 
BERNARDI, A.C. de C.; MACHADO, P.L.O. de A.; SILVA, C.A. Fertilidade do solo e demanda por nutrientes no Brasil. In: MANZATTO, C.V.; FREITAS JUNIOR, E. de; PERES, J.R.R. (Ed.). Uso agrícola dos solos brasileiros. Rio de Janeiro: Embrapa Solos, 2002. p.61-77.

BOARETTO, A.E.; VAN RAIJ, B.; SILVA, F.C.; CHITOLINA, J.C.; TEDESCO, M.J.; CARMO, C.A.F.S. do. Amostragem, acondicionamento e preparo de amostras de plantas para análise química. In: SILVA, F.C. da. Manual de análises químicas de solos, plantas e fertilizantes. 2.ed. Brasília: Embrapa Informação Tecnológica, 2009. p.59-85.

BREVILIERI, R.C. Adubação fosfatada na cultura da soja em Latossolo Vermelho cultivado há $\mathbf{1 6}$ anos sob diferentes sistemas de manejo. 2012. 43p. Dissertação (Mestrado) - Universidade Estadual do Mato Grosso do Sul, Aquidauana.

CANTARUTTI, R.B.; BARROS, N.F. de; MARTINES, H.E.P.; NOVAIS, R.F. Avaliação da fertilidade do solo e recomendação de fertilizantes. In: NOVAIS, R.F.; ALVAREZ V., V.H.; BARROS, N.F.; FONTES, R.L.; CANTARUTTI, R.B.; NEVES, J.C.L. (Ed.). Fertilidade do solo. Viçosa: SBCS, 2007. p.770-850.

CARNEIRO, M.A.C.; SOUZA, E.D. de; REIS, E.F. dos; PEREIRA, H.S.; AZEVEDO, W.R. de. Atributos físicos, químicos e biológicos de solo de cerrado sob diferentes sistemas de uso e manejo. Revista Brasileira de Ciência do Solo, v.33, p.147-157, 2009. DOI: 10.1590/ S0100-06832009000100016.

COSTA, S.E.V.G. de A.; SOUZA, E.D. de; ANGHINONI, I.; FLORES, J.P.C.; ANDRIGUETTI, M.H. Distribuição de potássio e de raízes no solo e crescimento de milho em sistemas de manejo do solo e da adubação em longo prazo. Revista Brasileira de Ciência do Solo, v.33, p.1291-1301, 2009. DOI: 10.1590/ S0100-06832009000500022.

CUSTO de produção de milho - safra 2013/2014. Cuiabá: Instituto Mato-Grossense de Economia Agropecuária, 2013. Disponível em: $\quad<$ http://www.imea.com.br/upload/publicacoes/arquivos/ R410_2013_01_CPMilho.pdf>. Acesso em: 20 jan. 2014.

FERREIRA, D.F. Sisvar: a computer statistical analysis system. Ciência e Agrotecnologia, v.35, p.1039-1042, 2011. DOI: 10.1590/ S1413-70542011000600001.

KAPPES, C.; ZANCANARO, L. Manejo da fertilidade do solo em sistemas de produção no Mato Grosso. In: CONGRESSO NACIONAL DE MILHO E SORGO, 3.; SIMPÓSIO SOBRE LEPDÓPTEROS COMUNS A MILHO, SOJA E ALGODÃO, 1., 2014, Salvador. Eficiência nas cadeias produtivas e o abastecimento global: palestras. Sete Lagoas: Associação Brasileira de Milho e Sorgo, 2014. p.358-381.

LANGE, A.; CABEZAS, W.A.R.L.; TRIVELIN, P.C.O. Recuperação do nitrogênio das fontes sulfato e nitrato de amônio pelo milho em sistema semeadura direta. Pesquisa Agropecuária Brasileira, v.43, p.123-130, 2008. DOI: 10.1590/ S0100-204X2008000100016.

LOURENTE, E.R.P.; MERCANTE, F.M.; ALOVISI, A.M.T.; GOMES, C.F.; GASPARINI, A.S.; NUNES, C.M. Atributos microbiológicos, químicos e físicos de solo sob diferentes sistemas de manejo e condições de cerrado. Pesquisa Agropecuária Tropical, v.41, p.20-28, 2011.

MARSCHNER, P. Mineral nutrition of higher plants. 3.ed. London: Academic Press, 2012. 672p.

MATIAS, M. da C.B.; SALVIANO, A.A.C.; LEITE, L.F.C.; GALVÃO, S.R. da S. Propriedades químicas em Latossolo Amarelo de Cerrado do Piauí sob diferentes sistemas de manejo. Revista Ciência Agronômica, v.40, p.356-362, 2009.

MOREIRA, F.L.M.; MOTA, F.O.B.; CLEMENTE, C.A.; AZEVEDO, B.M. de; BOMFIM, G.V. do. Adsorção de fósforo em solos do Estado do Ceará. Revista Ciência Agronômica, v.37, p.7-12, 2006.

NOVAIS, R.F.; SMYTH, T.J.; NUNES, F.N. Fósforo. In: NOVAIS, R.F.; ALVAREZ V., V.H.; BARROS, N.F.; FONTES, R.L.; CANTARUTTI, R.B.; NEVES, J.C.L. (Ed.). Fertilidade do solo. Viçosa: SBCS, 2007. p.471-550.

OLIVEIRA JÚNIOR, A. de; CASTRO, C. de; KLEPKER, D.; OLIVEIRA, F.A. de. Soja. In. PROCHNOW, L.I.; CASARIN, V.; STIPP, S.R. (Ed.). Boas práticas para o uso eficiente de fertilizantes. Piracicaba: International Plant Nutrition Institute, 2010. v.3: culturas. p.1-38.

PREÇOS médios mensais pagos pela agricultura [em 2013]. São Paulo: Instituto de Economia Agrícola, [2013]. Disponível em: $<$ http://ciagri.iea.sp.gov.br/nia1/Precos_Medios.aspx?cod_sis=5 $>$. Acesso em: 15 abr. 2013.

SÁ JÚNIOR, A. de; CARVALHO, L.G. de; SILVA, F.F. da; ALVES, M. de C. Application of the Köppen classification for climatic zoning in the state of Minas Gerais, Brazil. Theoretical and Applied Climatology, v.108, p.1-7, 2012. DOI: 10.1007/s00704-011-0507-8.

SANTOS, H.G. dos; JACOMINE, P.K.T.; ANJOS, L.H.C. dos; OLIVEIRA, V.A. de; LUMBRERAS, J.F.; COELHO, M.R.; ALMEIDA, J.A. de; CUNHA, T.J.F.; OLIVEIRA, J.B. de. Sistema brasileiro de classificação de solos. Brasília: Embrapa, 2013. 353p.

SILVA, F.C. da. (Ed.). Manual de análises químicas de solos, plantas e fertilizantes. 2.ed. Brasília: Embrapa Informação Tecnológica; Rio de Janeiro: Embrapa Solos, 2009. 627p.

SOUSA, D.M.G. de; LOBATO, E. (Ed.). Cerrado: correção do solo e adubação. 2.ed. Brasília: Embrapa Informação Tecnológica; Planaltina: Embrapa Cerrados, 2004. 416p.

WENDLING, A.; ELTZ, F.L.F.; CUBILLA, M.M.; AMADO, T.J.C.; MIELNICZUK, J. Recomendação de adubação potássica para trigo, milho e soja sob sistema plantio direto no Paraguai. Revista Brasileira de Ciência do Solo, v.32, p.1929-1939, 2008. DOI: $10.1590 / \mathrm{S} 0100-06832008000500014$.

WERLE, R.; GARCIA, R.A.; ROSOLEM, C.A. Lixiviação de potássio em função da textura e da disponibilidade do nutriente no solo. Revista Brasileira de Ciência do Solo, v.32, p.2297-2305, 2008. DOI: 10.1590/S0100-06832008000600009.

WILDA, L.R.M. Amostragem georreferenciada e aplicação à taxa variável de corretivos e fertilizantes: dinâmica da fertilidade do solo em lavoura de grãos do Cerrado. 2014. 84p. Dissertação (Mestrado) - Universidade Federal de Lavras, Lavras. 